\title{
O SENTIDO DA SEXUALIDADE DE MULHERES SUBMETIDAS A HISTERECTOMIA: UMA CONTRIBUIÇÃO DA ENFERMAGEM PARA A INTEGRALIDADE DA ASSISTÊNCIA GINECOLÓGICA ${ }^{a}$
}

\author{
The meaning of women's sexuality that were submited to the \\ histerectomy: a nursing contribution for the completeness of \\ the gynecological assistance ${ }^{a}$ \\ El sentido de la sexualidad de mujeres sometidas a \\ histerectomia: una contribución de la enfermería a la \\ integralidad de la asistencia ginecológica ${ }^{a}$
}

\begin{abstract}
RESUMO
A histerectomia é um procedimento cirúrgico irreversível, realizado por indicação médica, com a finalidade de restabelecer a saúde ou mesmo salvar a vida da mulher. Ser submetida a esta cirurgia acarreta modificações em seu cotidiano porque as recomendações pertinentes ao pós-operatório de histerectomia impõem implicações em seu mundo-vida. Este estudo de natureza qualitativa teve como objetivo analisar o sentido da sexualidade de mulheres após a histerectomia à luz do pensamento de Martin Heidegger. Foram depoentes 25 mulheres submetidas à retirada total do útero; a entrevista fenomenológica ocorreu num tempo variado, de 4 a 19 meses após o procedimento cirúrgico. A interpretação da estrutura de significação "a atividade sexual foi considerada" desvelou que na dinâmica assistencial, médica e de enfermagem, as rotineiras orientações de abstinência sexual determinadas pelo pós-operatório devem ser consideradas a partir da subjetividade da mulher que será/foi submetida à histerectomia.
\end{abstract}

Palavras-chave: Enfermagem. Histerectomia. Sexualidade.

\begin{abstract}
Histerectomy is a irreversible surgical procedure carried through by medical indication with the purpose to reestablish the health or even to save the woman's life. To be submitted to this surgery causes modifications at woman's daily life because the pertinent recommendations to the Histerectomy post operative impose implications in her world-life. This qualitative study had as object to analyze the meaning of women's sexuality after Histerectomy, supported by Martin Heidegger's thoughts. The informants were 25 women submitted to a total withdrawal of the uterus between nineteen to four months before the data collection. The interpretation of the meaning structure "sexual activity was considered", showed that in the medical and nursing assistential dynamics the routine orientations of sexual abstinence determined by the post operative must be considered from the subjectivity of the woman who will /was submitted to the Histerectomy.
\end{abstract}

Keywords: Gynecological nursing. Histerectomy. Sexuality. Daily. Martin Heidegger

\section{Resumen}

La histerectomia es un procedimiento quirúrgico irreversible realizado por indicación médica con la finalidad de restablecer la salud o mismo salvar la vida de la mujer. Ser sometida a esta cirurgía acarrea modificaciones en su cotidiano porque las recomendaciones para después de una operación de histerectomia imponen implicaciones en su mundo-vida. Este estudio de naturaleza cualitativa tuvo como objetivo analizar el sentido de la sexualidad de mujeres tras la histerectomia a la luz del pensamiento de Martin Heidegger. Fueron oídas 25 mujeres sometidas a la retirada total de útero siendo que la encuesta fenomenológica ocurrió en un tiempo entre cuatro y diecinueve meses tras el procedimiento quirúrgico. La interpretación de la estructura de la significación "la actividad sexual fue considerada" enseñó que en la dinámica asistencial médica y de enfermería, las orientaciones de rutina de abstinencia sexual determinada por el periodo que sigue a la operación deben ser consideradas a partir de la subjetividad de la mujer que será/fue sometida a histerectomia

Palabras-claves: Enfermería Ginecológica. Histerectomia. Sexualidad. Cotidiano. Martin Heidegger.

${ }^{1}$ Doutora em Enfermagem. Professora Associada do Departamento de Enfermagem Aplicada da FACENF/UFJF. Pesquisadora do NUPESM/EEAN/UFRJ e do Grupo de Pesquisa "0 cotidiano do cuidar em Enfermagem" da FACENF/UFJF. Minas Gerais, Brasil e-mail: annasalimena@terra.com.br.² Doutora em Enfermagem. Orientadora da tese. Professora Titular de Enfermagem Obstétrica do Departamento de Enfermagem Materno-Infantil da EEAN/UFRJ. Pesquisadora e Membro da Diretoria do NUPESM/EEAN/UFRJ. Rio de Janeiro, Brasil. 


\section{CONSIDERAÇÕES INICIAIS}

A ocorrência de uma cirurgia é motivo de forte mobilização emocional para o paciente e sua família. Percebem-se sentimentos de inquietação, de insegurança e de medo, como descrito na literatura sobre esta temática ${ }^{1-2}$. Atribuem-se tais manifestações à natureza intervencionista do tratamento terapêutico proposto e às necessidades emocionais da clientela submetida ao tratamento cirúrgico, uma vez que o enfoque, via de regra, está centrado na dimensão biológica da doença.

A cirurgia ginecológica é um ramo da cirurgia geral que trata do aparelho genital feminino, das afecções cirúrgicas da mulher, considerando as mamas e a pelve. Não existem registros com exatidão da época em que aquela se iniciou, mas se sabe que tanto a obstetrícia quanto a ginecologia foram separadas da cirurgia geral no começo do século XIX.

A terminologia cirúrgica é formada por prefixo que indica o órgão em causa e sufixo que indica o ato cirúrgico realizado². Assim, a cirurgia realizada para retirada do útero é denominada histerectomia. A primeira cirurgia ginecológica abdominal realizada foi a ooforectomia por McDowell, em 1840, e depois foram realizadas a histerectomia e a correção de fístulas vesicovaginais ${ }^{3}$.

Há de se considerarem os mitos e as idéias assimiladas pela mulher sobre a cirurgia ginecológica, principalmente a histerectomia, pois eles estão atrelados a sentimentos e valores de cada mulher. A incidência de morbidade psicológica é mais alta antes da cirurgia, pois a perda do útero significa para a mulher o fim de um potencial reprodutivo e diminuição da sexualidade. $^{4}$

No desenvolvimento do evento cirúrgico, faz-se necessária a atuação dos profissionais envolvidos nos procedimentos anestésico-cirúrgicos, ou seja, uma equipe multiprofissional que irá agir no suporte e desenvolvimento das atividades que lhe são concernentes. As ações desenvolvidas por esta equipe têm seu início no período pré-operatório, estendem-se durante os procedimentos trans e pós-operatórios, prestando assistência ao cliente até a sua alta hospitalar, bem como, algumas vezes, por um longo período após a alta.

No hospital, o centro cirúrgico é uma unidade que atende aos usuários com peculiaridades e particularidades: de faixa etária, gênero, cultura, raça, valores, com agravos de saúde e necessidades terapêuticas, relacionadas às diversas especialidades, e de onde identificamos pessoas em estados emocionais distintos. Neste conjunto de atuação, a equipe de enfermagem tem papel relevante no desempenho de suas atividades, considerando que qualquer ato cirúrgico conta com a atuação de bastidores: do Centro de Material Esterilizado, além da circulação de sala de operação.

As indicações para histerectomia são: falha do tratamento clínico ou da ablação endometrial em pacientes com sangramento uterino anormal; miomas uterinos associados à dor ou com sangramento uterino anormal; úteros de volume até $500 \mathrm{~cm}^{3}$.
A histerectomia abdominal total (HAT) é indicada para colo de útero anormal; hipermotilidade do colo uterino; paciente que não realiza colpocitologia oncótica anualmente; nas situações de doença anatômica, estado maligno e em condições de alto risco para o desenvolvimento ou recorrência deste, deve ser feita a HAT com salpingooforectomia bilateral ${ }^{5}$.

A histerectomia subtotal está indicada nos casos de: colo de útero normal à colpocitologia oncótica e colposcopia; pacientes jovens (abaixo de 45 anos) ${ }^{6}$ ou quando [...] a parte vaginal e uma quantidade variável do cérvice supravaginal não são removidas: ${ }^{7: 921}$. A histerectomia também pode ser realizada por via vaginal (HV), este tipo de procedimento cirúrgico é considerado de menor traumatismo em virtude da ausência de incisão abdominal bem como da não-exposição da cavidade peritonial. Ambas as vias de acesso têm vantagens e desvantagens, sendo que cada uma tem suas próprias indicações e contra-indicações ${ }^{6}$. Como alternativa, também, na via vaginal, pode-se usar como recurso a histerectomia vaginal laparoscópica-assistida (HVLA) ou a histerectomia vaginal pelviscópica-assistida (HVPA), nas quais são realizados pequenos orifícios no abdome, retirando o útero através da vagina?.

A indicação dessa terapêutica cirúrgica, a histerectomia, normalmente inclui o conhecimento específico da fisiologia e das patologias dos órgãos do aparelho genital feminino, e das manifestações clínicas das afecções da pelve da mulher, para que haja sucesso nesse procedimento. Assim, trata-se de um procedimento definitivo de perda irreversível do útero, que pode ser para restabelecer a saúde ou mesmo salvar a vida da mulher. Mas a histerectomia determina uma série de implicações com alterações, desde as condições físicas até fortes perturbações emocionais, com modificações em sua vida.

Devido ao manuseio das alças intestinais durante a histerectomia, pode haver alteração da função intestinal. Entre outras informações, a paciente deve ser orientada a não se esforçar durante 0 ato de defecação. 0 sistema urinário também pode apresentar alterações, pois para a histerectomia, via de regra, é realizada a cateterização vesical, tornando-se necessária a reeducação posterior para a reintegração da micção ${ }^{8}$.

Normalmente, surgem as preocupações em relação à dor e ao desconforto, pois todo processo cirúrgico envolve corte e recuperação posterior; isso aumenta a apreensão, sensibilidade e ansiedade. Se as manifestações das alterações psicológicas não forem percebidas e cuidadas, poderão se tornar distúrbios psiquiátricos. Também é de suma importância perceber as manifestações físicas e fisiológicas que poderão surgir, visto que no pós-operatório a mulher terá algumas restrições, como, por exemplo, não fazer exercícios que forcem a musculatura abdominal e, principalmente, a da pelve ${ }^{1}$.

No pós-operatório, a mulher terá alguns cuidados restritivos, determinando alterações em seu cotidiano de mulher-mãe- 
esposa e profissional. Será preciso que ela receba orientações de ações para este período, de modo geral, e, especificamente, para as situações de cirurgias ginecológicas da pelve. Obviamente, essas orientações devem ser ditas em uma linguagem clara e compreensiva para a cliente, atendendo às suas necessidades de orientação e contemplando-a como ser existencial no seu cotidiano com suas necessidades, sentimentos, percepções, decisões 9 .

Por ser considerada a histerectomia uma cirurgia de grande porte, além de um período maior de internação no pós-operatório, são recomendados repouso e limitação de alguns hábitos, o que afasta a mulher de imediato do convívio social, trazendo, em algumas circunstâncias, inibições e desajustes sociais. Também, existe repercussão no labor, tanto doméstico quanto fora do lar, tendo em vista que nos dias atuais a mulher é força no mercado de trabalho8.

As recomendações pertinentes ao pós-operatório de histerectomia trarão interferências, as mais diversas, em seu mundo-vida, remetendo ao ser-aí-com ${ }^{10}$, uma vez que este ser se apresentará como mediador de suas relações como mulher, esposa, mãe, e com os profissionais. Nesse sentido, delimitou-se o objetivo de desvelar o sentido da sexualidade de mulheres submetidas a histerectomia. 0 enfoque dado nesta investigação buscou perceber suas necessidades de modo a valorizar a sua singularidade.

Cabe compreender, pois, que a cirurgia como procedimento terapêutico resolve um problema de um órgão doente, mas acarreta, no pré, no trans e no pós-operatório, implicações para sua condição de mulher. Muito além de ser um procedimento objetivo, em seu bojo existem relevantes considerações subjetivas para quem o vivencia. Trata-se, então, de ir além do biológico e se dedicar a encontrar faces do fenômeno que contribuam para o cuidado, compreendendo a saúde em seu sentido amplo, integral e humano.

De modo geral, as mulheres atribuem ao útero vários significados. Entre tantos, tem-se o útero como órgão sexual para procriação, fonte de competência feminina e de vitalidade, como também o da atração. Por isso, a sua retirada pode também ser significativa e trazer para as mulheres alterações na vida sexual e emocional. Além das alterações determinadas pelos fatores psíquicos, físicos, fisiológicos, sociais e culturais ${ }^{11}$.

Em conjunto com estas reflexões, observa-se ainda que as cirurgias são planejadas em consonância com as rotinas dos serviços de saúde e, na maioria das vezes, não é dada à mulher a possibilidade de decidir o momento mais adequado e o tempo necessário à reorganização de seu cotidiano pessoal e profissional. Parece assim que ela não tem opção.

Acredita-se que estas situações intensifiquem o estado emocional e sejam fontes geradoras de ansiedade para a mulher que precisa submeter-se a um procedimento cirúrgico. Socialmente existem crenças que foram introjetadas ao longo da história de vida de cada mulher, que podem justificar a existência do medo da dor, da anestesia, do desconhecido e da própria cirurgia'.
$\mathrm{Na}$ apreciação sobre a condição de saúde e doença nas classes sociais baixas, fica enfatizado o poder de decisão do médico sobre os tratamentos, a desconsideração do conhecimento que o próprio doente tem de seu corpo, bem como a despreocupação em ouvir ou conhecer as suas condições socioeconômicas e culturais ${ }^{12}$. Mas, já foi sinalizado que a mulher tem tomado novas posturas/decisões em relação aos cuidados com sua saúde ${ }^{13}$.

Estudos atestam as discriminações das quais as mulheres são vítimas, revelando assim as diferenças e a inferioridade em relação aos homens. Traduz-se, assim, a situação da mulher nos dias atuais, na vida social, sexual, afetiva e, principalmente, no mercado de trabalho ${ }^{14}$.

Ao considerarmos um estudo sobre mulheres após a histerectomia, estamos lidando com um fenômeno que é, ao mesmo tempo, biológico, social e cultural. 0 modo como a mulher concebe a perda do seu útero está articulado com a categoria gênero, uma vez que é $0[. .$.$] trabalho reprodutivo 0$ lugar onde a diferença se instala ${ }^{15: 103}$. Gênero é um conceito das ciências sociais [...] que se refere à construção social do sexo e que ajuda a distinguir a dimensão biológica do social ${ }^{15}$ 102.

Acrescenta-se, ainda, que o referencial temático sobre a histerectomia está exclusivamente centrado na doença e nos procedimentos técnicos, sendo estes insuficientes para esclarecer questões referentes à existência do ser-mulher, que, sendo um ser existente, não é contemplada na dimensão ontológica da vivência e do vivido. Porque [...] o que interessa é diagnosticar e curar... os valores desejados são a vida, uma longa vida, a capacidade de reprodução, a capacidade de trabalho físico, a força, a ausência de dor... além da agradável sensação de existir ${ }^{16: 83}$.

\section{O CAMINHO METODOLÓGICO}

A trajetória de pesquisa que teve maior sintonia com 0 objetivo do estudo foi a abordagem qualitativa. A metodologia [...] é o caminho do pensamento e a prática exercida na abordagem da realidade ${ }^{17: 16}$. Portanto, a pesquisa qualitativa vem ao encontro dos anseios e expectativas do pesquisador, permitindo um relacionamento mais harmonioso e natural do pesquisador com as questões de estudo.

Considerou-se, então, que a pesquisa qualitativa, tendo a fenomenologia como referencial metodológico, abriria perspectivas para que se buscasse compreender os diferentes significados atribuídos pela mulher ao pós-operatório de histerectomia de modo a ser capaz de captar o sentido da sexualidade.

A fenomenologia significa a volta ao mundo da experiência, na qual se busca chegar à essência através das experiências vividas pelo sujeito, possibilitando, assim, que as coisas sejam vistas como elas acontecem ${ }^{18}$. E para compreender a humanidade dos seres humanos, a fenomenologia convoca e 
remete para uma visão holística, possibilitando a exploração e discussão do cotidiano assistencial de enfermagem, emergindo uma práxis criativa e intencional.

Operacionalmente, na abordagem fenomenológica, o conhecimento que se tem sobre a temática constitui o momento pré-reflexivo. Na maneira diferenciada de olhar a situação problematizada, está assumir o olhar de observador que põe em suspensão qualquer teoria, crença, concepção, conhecimento prévio sobre a situação em estudo, para ir em busca da précompreensão ${ }^{10}$. Deve-se também, inicialmente, recusar as préconcepções sobre a natureza do fenômeno que se está investigando, e, nesta investigação, solicitou-se que as mulheres descrevessem, em linguagem própria, como elas estavam experimentando essa situação vivenciada.

Portanto, o pesquisador deve ter com o sujeito interrogado um olhar atentivo e estar aberto para o diálogo, acolhimento das idéias, opiniões e sentimentos, colocando-se em seu lugar para ver, sentir e pensar; desse modo, estará mais próximo da sua compreensão. Também, nesta aproximação com o discurso dito (escrito ou falado) há de se considerar o não-dito, através do silêncio e dos gestos, que são formas de expressão e de compartilhamento ${ }^{10}$.

Dessa forma, só depois de compreender o que está velado é que o pesquisador poderá fazer a interpretação da questão pesquisada; e [...] interpretar não é tomar conhecimento de que se compreendeu, mas elaborar as possibilidades projetadas na compreensão ${ }^{10: 204}$. Por isso, a interpretação é o último momento da pesquisa. Continuando, o autor expressa que: [...] a compreensão vaga e mediana é um fato ${ }^{10: 31}$, ou seja, é aquilo que o ente pensa e fala do ser, mas ainda não é a interpretação, que será alcançada no segundo momento pela hermenêutica.

Neste estudo, dirigiu-se um olhar atentivo para as mulheres submetidas a histerectomia, interrogando este ente (mulher), por causa das inquietações em relação às questões que este Ser demanda, preocupada com a sua singularidade, e em busca do sentido do seu comportamento no cotidiano após a histerectomia.

Esta pesquisa foi desenvolvida com mulheres que se submeteram a histerectomia no Hospital Universitário da Universidade Federal de Juiz de Fora - MG (HU-UFJF) e por ser tema emergente da prática profissional e do qual surgiram as inquietações. Estas mulheres foram internadas na Unidade de Ginecologia deste hospital. Sendo assim, o projeto de pesquisa foi apreciado pelo Chefe do Serviço de Ginecologia e pelo Diretor Geral do HU-UFJF, que autorizaram o seu desenvolvimento.

Após este consentimento, foi encaminhado ao Comitê de Ética da UFJF e aprovado em 22/06/06 conforme parecer $n^{0}$ 055/2006, atendendo às solicitações da Comissão Nacional de Ética em Pesquisa, do Conselho Nacional de Saúde do Ministério da Saúde.

Os sujeitos desta pesquisa foram as mulheres submetidas a histerectomia, 5 no ano de 2005 e 20 nos meses de janeiro a julho de 2006. Foram feitos contatos por telefone para agendamento dos encontros em suas residências. Em alguns casos, foi bastante difícil esta localização, mas, com empenho, conseguiu-se encontrá-las e promover o encontro fenomenológico inerente à entrevista empática e colher/ouvir seus depoimentos, que foram ouvidos e gravados em fita magnética, sendo transcritos pela pesquisadora, no mesmo dia, a fim de se manter a fidedignidade dos discursos.

Antes de proceder à coleta dos depoimentos, foi explicada a cada uma das mulheres participantes a pretensão de se desenvolver um trabalho com elas, sem, contudo, dizer-lhes o conteúdo da entrevista. Foi também oferecida plena liberdade de participação ou recusa e solicitado que assinassem o termo de autorização para o registro de seus depoimentos, garantindoIhes sigilo e anonimato, para proteção da sua privacidade. Tal procedimento visou atender à Resolução n. 196/96 do Conselho Nacional de Saúde (1996), que dispõe sobre pesquisa envolvendo seres humanos e recomenda o Termo de Consentimento Livre e Esclarecido.

Esses encontros e entrevistas, agendados, ocorreram no mínimo quatro meses após a histerectomia. Desvencilhando-se das amarras do tecnicismo, da técnica provocadora, do modelo biomédico, que determinam o pós-operatório mediato, imediato e tardio, foi-se ao encontro dessas mulheres num período de tempo variável em meses após a histerectomia, constituindo 0 tempo fenomenológico, que expressa o cotidiano delas. Então, conheceram-se as mulheres, estabeleceu-se uma relação empática e ouviram-se seus depoimentos, sobre sua condição cirúrgica e o seu cotidiano no pós-histerectomia, sem interferência dos familiares, pois foram feitos em suas salas isoladas ou até em seu quarto de dormir.

\section{ANÁLISE COMPREENSIVA}

A análise dos dados ocorreu concomitante à coleta dos depoimentos. Após a descrição do fenômeno vivido pelas entrevistadas, foram destacadas as significações, constituindose então a compreensão vaga e mediana, o primeiro momento metódico em Heidegger. Surgiu, assim, a compreensão do ser - fio condutor da compreensão interpretativa, o segundo momento metódico desenvolvido sustentado no referencial metodológico. Os estudos reportam esses dois momentos: 0 primeiro para explicitação do fato, em que o ente se mostra na maioria das vezes para todos, e o segundo momento como 0 desvelar do ser ou fenômeno, no qual precisamos construir o fato para trazê-lo à luz.

Na análise da pre-sença, o primeiro desafio é a questão do ser. Portanto, [...] nem sempre se deve impor à pre-sença categorias delineadas ${ }^{10: 44}$. Para se conhecer esse Ser que é pre-sença, é preciso voltar a considerar os depoimentos, pois é ali no conteúdo das entrevistas que estão os significados.

Assim, compreendeu-se que se teria que reduzir os pressupostos, pois senão se estaria aplicando uma idéia prévia, 
ou seja, uma categoria prévia colocada, como por exemplo: que no cotidiano da mulher após a histerectomia, ela tenha dificuldades no relacionamento sexual. Esta era uma pressuposição inicial, calcada na tradição de que, evidentemente, ela fez uma cirurgia abdominal na qual foi realizada a retirada do útero, que anatomicamente está ligado à vagina através do colo, e que a relação sexual será uma atividade a ser postergada, a ser enfrentada. Evidentemente pressupõe-se que esta categoria deveria existir porque [...] a tradição assim predominante tende a tornar tão pouco acessível o que ela 'lega', que, na maioria das vezes e em primeira aproximação, 0 encobre e esconde ${ }^{10: 49}$.

Ao reduzir este pressuposto, ou seja, a idéia que se tem da dificuldade no relacionamento sexual em decorrência da histerectomia, foi possível considerar o vivido da mulher que foi histerectomizada e, através dos significados, compreender a sua condição e seus sentimentos após essa cirurgia em relação à sexualidade.

\section{Compreensão vaga e mediana - 10 momento metódico}

A modalidade de acesso, então, mostra a pre-sença em sua cotidianidade mediana, tal como ela é: antes de tudo e na maioria das vezes ${ }^{10}$. Da cotidianidade expressa nas falas, nos depoimentos, procuraram-se as estruturas essenciais, e não as ocasionais. Portanto, através dos depoimentos, puderam-se destacar as estruturas significativas e agrupá-las em Unidades de Significação.

Estas são as expressões do que foi captado como significação das mulheres acerca da sua sexualidade no cotidiano após a histerectomia. A seguir, a Unidade de Significação "a atividade sexual foi considerada" está apresentada com as ilustrações que a constituíram:

\section{[...] Sexo eu não sei. [...] $\mathrm{E}_{1}$}

[...] Não tive problema nenhum. Nem na vida sexual $[\ldots] \mathrm{E}_{2}$

[...] eu falei com ele, você podia, né... ele falou: "você que sabe". Pois aí no outro dia à noite, ele tentou e nada. Pois aí não deu, ele falou: "não vou continuar não porque não está dando[...] $\mathrm{E}_{4}$

[...] Também voltei a ter sexo tranqüilo... com conforto, pois antes era só debaixo do chuveiro, em pé. Aíjá viu... não era muito bom [...] $\mathrm{E}_{5}$

[...] Sexualmente estou 100\% inativa, né... risos... por causa das circunstâncias e mesmo porque, emocionalmente falando, eu não tô preparada para me envolver com alguém, porque está muito recente a morte do meu marido e também porque me incomoda esta coisa da incisão [...] $\mathrm{E}_{6}$
[...] na matéria sexual eu não mexo mais, já estava antes, parada e continuo, sabe. Depois que meu marido morreu eu não me envolvi com mais ninguém não, sabe [...] $\mathrm{E}_{7}$

[...] Quanto ao sexo, eu não me interesso por sexo. Sou viúva a vinte e quatro anos. Não tenho namorado e nem pretendo ter, não pretendo ter mesmo[...] $\mathrm{E}_{8}$

[...] Pro sexo melhorou muito porque antes eu só sentia dor. Agora nada, é muito bom, éótimo. Antes, não tinha nem prazer [...] $E_{9}$

[...] Eu não tenho homem há muitos anos, eu fiquei com medo por causa da AIDS, eles falavam muito dessa coisa de AIDS, e esse negócio da AIDS, eu passei a ter medo disso aí[...] $\mathrm{E}_{10}$

[...] Fiquei seis meses sem ter relações com meu marido, ele está no CERESP (presídio), né. Não tem cama, é no chão e agora que voltei a $\operatorname{ter}[. ..] \mathrm{E}_{11}$

[...] Sexo normal, não tem nada diferente, é tudo normal... relação sexual tranqüilo, tudo normal [...] $\mathrm{E}_{12}$

[...] No momento... éque agora tenho que ficar com o menino $[. ..] \mathrm{E}_{13}$

[..] Não tive mais parceiro nenhum depois que meu marido morreu, nunca tive outro, só ele mesmo[...] $\mathrm{E}_{14}$

[...] só o relacionamento que muda né, em casa, pro sexo. Eu não tenho vontade. Eu durmo aqui e ele dorme lá. Ele me procura, mas eu não tenho vonta$\operatorname{de}[\ldots] \mathrm{E}_{16}$

[...]Aí entrei em depressão, não queria cuidar de mais nada, sabe... ficou horrivel Nem tomar sol, nem namorar, transar então... a gente fica meio esquisita[...] $\mathrm{E}_{17}$

[...] Relação sexual não tenho. Sinto vontade normal, mas não quero saber de homem [...] $\mathrm{E}_{18}$

[...] Até pro sexo melhorou muito. Aquele desconforto na calcinha até acabou, pois era um desconforto que a gente tinha, a calcinha molhava muito, sabe. Melhorou muito. Igual já te falei, eu sentia envergonhada [...] $E_{19}$ 
[...] Esse negócio de sexo eu não quero nem saber. Não sinto falta disso não, entendeu? Meu marido morreu tem 17 anos, arrumei outro que não deu certo não, então... não quero saber de ninguém não $[\ldots] \mathrm{E}_{20}$

[...] Nunca tive namorado e nem sinto falta disso. Alguns rapazes até me olham, mas não me interesso por eles, pra que complicar a vida [...] $\mathrm{E}_{21}$

[...] Tudo normal pra sexo, não faz diferença nenhuma. Tudo tranqüilo [...] $\mathrm{E}_{22}$

[...] Eu esfriei muito pra relação sexual. O marido comigo é a mesma coisa. Eu não sinto vontade, mas também não deixo morrer, né. Sempre compareço quando ele me quer. Desde que comecei com estes problemas que atrapalhou um pouco, mas o resto tá tudo bom [...] $\mathrm{E}_{23}$

[...] A gente já não se engraçava fazia tempo, mesmo assim antes de adoecer, ele e eu, era a idade sabe? Mais o quentinho dele me faz falta[...] $\mathrm{E}_{24}$

[...] Meus colegas aqui do hospital, alguns que sabem do que passei com ele, às vezes até dos escândalos que ele vinha fazer aqui, compreendem por que eu não quis e não quero saber de nada disso. No início até me recomendavam que eu tinha que sair, conhecer outros homens, mas depois pararam [...] $\mathrm{E}_{25}$

As mulheres consideraram a atividade sexual expressandose acerca do sexo, da relação sexual: sexo tranqüilo, com conforto, antes era só dor; para outras mulheres, de modo normal: "não tive problema nenhum"; nada diferente, tranqüllo; algumas outras expressam que não foi possível esta retomada em decorrência de problemas após a cirurgia como: "[...] não deu, incomoda a incisão; entrei em depressão... a gente fica meio esquisita[...]".

Após a histerectomia, a atividade sexual se mostrou inerente ao dia-a-dia dessas mulheres, sendo praticada ou não. Existe, então, a possibilidade de acontecer ou não acontecer. No cotidiano dessas mulheres, a não-retomada ocorre por: falta de apetite, não praticá-la antes, não conseguirem ter relações, medo da AIDS, estarem viúvas, ou dor. A retomada também ocorre porque é normal ter sexo. Assim, a relação sexual após a histerectomia pode ser melhor do que antes, pode ser como antes e ser uma obrigação da mulher.

Elas expressaram uma avaliação de bom, ruim ou melhor, considerando a relação sexual como possível no dia-a-dia. Cada uma dessas mulheres tem uma expressão própria e particular, envolvendo o parceiro ou não na situação que se refere à atividade sexual.

\section{Hermenêutica heideggeriana - 20 momento metódico}

Compreendeu-se que a atividade sexual foi considerada, 0 que revelou a propriedade de considerar a relação sexual, a vida sexual e o sexo, embora algumas tenham expressado a possibilidade de não retomar essa relação após a cirurgia, revelando a impropriedade.

Quando as mulheres expressam sobre a atividade sexual, apreende-se que ela está na cotidianidade, significa dizer da convivência com outro ser, ou seja, do relacionamento com o marido, ou companheiro, ou parceiro, alguém com quem ela se relaciona intimamente. Então, dessa forma, a mulher é ser-aícom num modo de estar-no-mundo. Somos seres relacionais e estamos sempre em interação com outros seres e conosco mesmo ${ }^{13}$.

Manifestam-se algumas que estão tendo relações sexuais com maior intensidade e prazer do que antes da histerectomia e que, na cotidianidade, estão se realizando como mulheres. Estão sendo seres de possibilidades, estão falando de si próprias. $E$, considerando os dizeres, [...] o ser-com é um constitutivo existencial do ser-no-mundo. A co-pre-sença se comprova como modo de ser próprio dos entes que vêm ao encontro dentro do mundo 10: 178. Elas são ser-aíe ser-aí-com; no cotidiano, ser de possibilidades. Heidegger coloca que [..] a própria pre-sença, bem como a co-pre-sença dos outros, vem ao encontro, antes de tudo e na maioria das vezes, a partir do mundo compartilhado nas ocupações ${ }^{10: 178}$.

Mas, algumas mulheres expressaram que não estão tendo relações sexuais, o que leva a pensar que não estão sendocom-o-outro. Mas, são seres de possibilidades. Expressam que não estão tendo atividade sexual porque não querem, porque estão viúvas ou porque nunca tiveram relação sexual. Elas assumem a decisão em relação à atividade sexual.

A mulher não desenvolveu o movimento da angústia, anunciando esse movimento mediante a possibilidade da decisão em relação à atividade sexual, mostrando, revelando através da propriedade e da impropriedade, que é ser-aí ou ser de possibilidades.

Ser de possibilidades é compreender-se sendo, é estar aberto às possibilidades que não são aquelas que se quer ou que se precisa, é o que vem ao encontro. Assim, houve mulheres que não tinham queixas, outras as apresentaram, informaram que ainda não estão bem e que tiveram, por conta de pequenos problemas, de voltar ao hospital. Outras, que tinham dificuldade na relação sexual mas que agora já não a têm. Percebe-se a possibilidade de a cirurgia não resolver todos os problemas. Houve uma abertura para expor a propriedade e a impropriedade. 


\section{CONSIDERAÇÕES FINAIS}

Esta descrição feita pela mulher parece necessária para que se compreenda que, para ela, existencialmente, é um processo. Há uma interligação mediante a qual seu movimento e seus modos de ser, no cotidiano, puderam ser captados porque ela os significou. A partir destes significados, foi possível desvelar sentidos por eles (os significados), encobertos no diaa-dia assistencial pela rotina dos serviços e pela atitude dos profissionais de saúde.

Nesta ótica, não representam pressupostos e apontam para alguns descompassos do atual modelo assistencial, para cuja correção este estudo pretende contribuir. 0 sentido que, de certo modo, desvela um descompasso assistencial refere-se às rotineiras orientações de abstinência sexual determinada pelo médico e ratificada por outros membros da equipe de saúde no período pós-operatório. Assim sendo, a atividade sexual, própria e inerente ao ser do humano, mostrou-se como possibilidade, e não como certeza.

Algumas mulheres retomaram a atividade sexual e outras não, sendo que o conhecimento biológico do modelo biomédico de assistência de saúde às mulheres, que estabelece um prazo de retomada, não foi explicitado pelas mulheres após a intervenção cirúrgica. Para aquelas que retomaram a atividade sexual, houve a possibilidade de até avaliarem que podia ser melhor do que antes, quando ocorria muito desconforto ou era normal. Tal compreensão é imanente da própria mulher que se revela não apenas como ser de possibilidades, mas como alguém que, com ajuda de outros, decide acerca da satisfação de sua sexualidade, tratando a atividade sexual como relação sexual, sexo e vida sexual.

Parece que a orientação para a relação sexual e a recomendação para o retorno devem ser dadas de modo a não inibir a atividade sexual, pois a retomada ocorre por decisão delas mesmas. A determinação médica sobre o momento da retomada pode inibir as mulheres, porém, pode ser também uma ajuda, considerando que detalhes da cirurgia como amputação de colo, que pode trazer implicações para o contato sexual, podem e devem ser discutidos. Então, as informações, as orientações e sugestões devem ser a partir da mulher, de sua singularidade, e não a partir das rotinas biológicas. Abordar as questões voltadas para a sexualidade antes da cirurgia faz com que já se saiba de algumas de suas situações em relação à sexualidade, como a de uma mulher que não pretende retomar mesmo ou de outra mulher que quer retomar depois de sanados os problemas pela cirurgia e que podem não conseguir retomar da melhor forma ou do modo que gostariam. Essas são as possibilidades.

As mulheres precisam ser vistas como seres de possibilidades e não só como portadoras de problemas no útero, com características singulares, e não de modo geral. Portanto, este estudo traz uma contribuição especial e, primeiramente, para a enfermagem ginecológica, que é dominada pela ginecologia e pelas ginecopatias mais prevalentes. A ginecologia preventiva não existe como política pública, o que existe é a doença ginecológica que faz a mulher procurar tratamento e que a faz ser tratada como tal, e não como mulher.

Hoje, no Brasil, o modelo para cuidar da saúde, colocado pelo Ministério da Saúde, é o Programa de Saúde da Família, visando ao olhar para a saúde e para a doença a partir de uma base epidemiológica. Assim, busca-se contabilizar cesarianas, laqueaduras e abortos, mas não se controla o quantitativo de histerectomia nem mesmo são analisados seus determinantes. E, menos ainda no cotidiano das mulheres após a histerectomia, há significação de seguimento ambulatorial ou de outras ações que reflitam acompanhamento e cuidado de prevenção de saúde.

Neste estudo, tais mulheres evidenciaram o quanto o cuidar da saúde é pontual, e não integral. É um cuidar a partir dos sintomas, que é a pressão, do preventivo, do controle e também do medo de problemas posteriores, de complicações. Essa clientela revelou, entretanto, o quanto as mulheres podem ainda estar distantes ou já próximas de se compreenderem como seres de possibilidades. Ora ainda se vêem como objeto para a equipe de saúde, ora acreditam nas possibilidades de serem sujeitos do cuidado da sua saúde. Para exigirem uma assistência integral, elas precisam de ajuda para decidirem, e não apenas que se trate ou se extirpe a parte do seu corpo que está com problemas.

Evidenciou-se que a equipe assistencial se pre-ocupa com as orientações para alta, mas não se ocupa em considerar o ser existencial da mulher. 0 estudo nos instiga à reflexão do quanto necessitamos rever nossa forma de cuidar, ampliando as reflexões e fomentando discussões interdisciplinares, despertando nos profissionais de saúde a sensibilidade para valorizar a fala e a escuta da mulher. É preciso que o relacionamento com a mulher seja de forma empática a partir do momento que ela procura o serviço de saúde.

E que as universidades, através de suas funções pautadas no tripé ensino/pesquisa/extensão, possam tornar oportunas as intervenções capazes de mobilizar os futuros profissionais em sua formação, considerando o ser-com-os-outros, a intersubjetividade, a autenticidade, a solicitude e o desvelo, para que as decisões sejam tomadas com a mulher e por ela.

\section{Referências}

1-Smeltzer SC, Bare BG. Tratado de Enfermagem Médico-Cirúrgica. Rio de Janeiro(RJ): Guanabara Koogan; 2004.

2-Parra OM, Saad WA. Instrumentação cirúrgica. Rio de Janeiro(RJ): Atheneu; 2000.

3-Linde RW, Mattingly RF. Ginecologia Operatória. $4^{\mathrm{a}}$ ed. Buenos Aires (AR): Bernardes; 1971.

4-Khastgir G, Studd JWW, Catalan J. The psychological outcome of hysterectomy. Gynecol Endocrinol 2003; 14: 132-41.

5-Lippi UG, Lopes RGC, Baracat FF. Ginecologia: manual de normas e condutas. São Paulo (SP): EPUB; 2002. 
6-Meeker MH, Rothrock JC. Cuidados de enfermagem ao paciente cirúrgico. $13^{\mathrm{a}}$ ed. Rio de Janeiro (RJ): Guanabara Koogan; 2007.

7- Jeffcoate SN. Princípios de ginecologia. São Paulo (SP): Manole; 1983.

8-Camano L, Souza E, Sass N, Mattar R. Obstetrícia: guias de medicina ambulatorial e hospitalar. São Paulo (SP) UNIFESP / Escola Paulista de Medicina: Manole; 2003.

9-Souto MD, Souza IEO. A sexualidade após mastectomia. Esc Anna Nery Rev Enferm. 2004; 8 (3): 402-10.

10-Heidegger M. Ser e tempo, 1. Petrópolis(RJ): Vozes; 1999.

11-Sbroggio AMR. Mitos em relação à retirada do útero em mulheres hospitalizadas no período pré-operatório. [disser tação de mestrado] Faculdade de Ciências Médicas / UNICAMP; 2004.
12-Boltanski L. As classes sociais e o corpo. São Paulo (SP): Paz e Terra; 2004.

13-Simões SMF, Souza IEO. Mulher: a de-cisão no cuidar da própria saúde. Niterói (RJ): Intertexto; 2002.

14-Nascimento ER. Gênero e enfermagem. Salvador (BA): Positiva; 1996.

15-Heilborn ML. Sexualidade: o olhar das ciências sociais. Rio de Janeiro (RJ): Zahar; 1999.

16-Canguilhem G. 0 normal e o patológico. Rio de Janeiro (RJ): Forense Universitária; 2006.

17-Minayo MCS. Pesquisa social: teoria, método e criatividade Petrópolis (RJ): Vozes; 1994.

18-Martins J, Boemer M, Ferraz CA. A fenomenologia como alternativa metodológica para a pesquisa; algumas considerações. Rev Esc Enferm USP 1990 ago; 24 (2): 139-47.

\section{Nota}

aRecorte da Pesquisa "O COTIDIANO DA MULHER APÓS A HISTERECTOMIA À LUZ DO PENSAMENTO DE MARTIN HEIDEGGER", Tese de Doutorado em Enfermagem - Escola de Enfermagem Anna Nery, Universidade Federal do Rio de Janeiro, agosto de 2007. 